\title{
INTERRELATIONSHIP OF THYROID HORMONES, OBESITY, AND PROLACTIN IN INFERTILE WOMEN
}

\author{
JUHI KATARIA ${ }^{1}$, GURPREET KAUR GILL ${ }^{1 *}$, MANBIR KAUR ${ }^{2}$ \\ ${ }^{1}$ Department of Medical Laboratory Sciences, Khalsa College of Pharmacy \& Technology, Amritsar, Punjab, India. ${ }^{2}$ Department of \\ Pharmacognosy, Khalsa College of Pharmacy, Amritsar, Punjab, India Email: gurpreet_pau25@yahoo.com
}

Received: 20 June 2017, Revised and Accepted: 03 October 2017

\begin{abstract}
Objective: The aim of the study was to evaluate and compare the level of thyroid hormones, namely, triidothyronine (T3), thyroxine (T4), thyroidstimulating hormone (TSH), and prolactin in blood serum of infertile women with normal healthy subjects in Amritsar region of Punjab, India. A number of complications arise from the dysfunction of hypothalamic-pituitary-ovarian axis, which leads to the hormonal disturbances in female reproductive system. Certain disorders such as obesity and thyroid hormone imbalance are highly prevalent and lead to various complications in pregnancy such as polycystic ovary syndrome. These disorders lead to the infertility and ultimately constitute a major physiological stress. A multidimensional diagnostic approach is imperative in evaluating these disorders. In the present study, the association between thyroid hormones and prolactin has been reviewed in infertile women which is a prerequisite to work up for infertility in Punjab.
\end{abstract}

Methods: Hemoglobin levels were estimated in the blood serum of healthy controls and infertile women by the method of Sahli. The levels of serum T3, $\mathrm{T} 4$, TSH, and prolactin were determined by electrochemiluminescence immunoassay using Cobas e 411 analyzer according to the instruction manual.

Results: Majority of infertile women were found to have hypothyroidism and hyperprolactinemia which can be correlated with infertility. This condition might respond to the treatment for their hormonal and prolactin levels, and fertility can be restored.

Conclusion: The measurement of TSH and prolactin should be done at an early stage of infertility rather than more invasive procedures involved in the treatment of infertility in women.

Keywords: Infertility, Thyroid, Obesity, Prolactin, Thyroid-stimulating hormone.

(c) 2018 The Authors. Published by Innovare Academic Sciences Pvt Ltd. This is an open access article under the CC BY license (http://creativecommons. org/licenses/by/4. 0/) DOI: http://dx.doi.org/10.22159/ajpcr.2018.v11i1.20861

\section{INTRODUCTION}

In India, everyone in six couples is affected from infertility which is defined as the biological inability to carry pregnancy to full term and give birth [1]. Certain disorders such as obesity and thyroid hormone imbalance are highly prevalent and lead to various complications in pregnancy such as polycystic ovary syndrome [2]. There are $40-50 \%$ of cases of infertility which are due to primary complications, and it can lead to social, emotional, and psychological stress. There may be lot of many reasons of infertility such as ovulation disorders, imbalance in thyroid hormones, altered prolactin levels, and pelvic adhesions [3]. The interrelationship of altered thyroid hormones with obesity and prolactin in infertility is uncovered and is imperative to study and compare to get over the best possible treatments.

Increased prolactin levels above $25 \mathrm{ng} / \mathrm{ml}$ diminish the pulsatile release of gonadotropin-releasing hormone and thus affect ovulation [4]. This increased level can be due to an elevated level of thyroid-stimulating hormone (TSH). Obesity is also an important cause as it can disturb the balance of hormones and enzymes. Increased circulating insulin due to abdominal obesity elevates androgen levels in the body [5]. Such factors lead to ovulatory dysfunctions and polycystic ovarian disease. Ovulation in women is regulated by various hormones such as follicle-stimulating hormone, luteinizing hormone, prolactin, and thyroid hormones. Both elevated and diminished levels of thyroid hormone affect menstrual cycles and ultimately fertility [6].

It has also been observed in various studies that serum TSH levels are a significant predictor of in vitro fertilization as TSH levels were significantly higher among women who produced oocytes that failed to be fertilized [7]. Hypothyroidism disturbs the estrogen metabolism and sex hormone binding globulin production. Altered levels of the biochemicals affect the feedback signals to the pituitary hypothalamus network, leading to its malfunctioning. Estimation of thyroid and prolactin in infertile women and healthy subjects is important to study and design the best possible treatments at the very early stage of infertility.

\section{METHODS}

In this study, we investigated the total of 60 women, including healthy and infertile women of reproductive age within a range of 20-45 years visiting Satjot Human Reproduction and Infertility Center, Amritsar. 30 fertile women with similar age and socioeconomic status were enrolled as controls. The study was categorized into two groups, namely, healthy controls and infertile women. Informed and written consents were obtained from the participating women in this study. Mean age and weight of 30 subjects in two groups (healthy controls and infertile) was calculated. Hemoglobin levels were estimated in the blood serum of healthy controls and infertile women by the method of Sahli's (acid hematin) using Sahli's hemoglobinometer [8]. The levels of serum T3, $\mathrm{T} 4$, TSH, and prolactin were determined by electrochemiluminescence immunoassay using Cobas e 411 analyzer according to the instruction manual [9]. Normal TSH and prolactin levels were $0.30-4.2 \mathrm{uIU} / \mathrm{ml}$ and $1.9-25 \mathrm{ng} / \mathrm{ml}$, respectively. Data were calculated and represented as mean \pm standard deviation.

Table 1: Age and weight of healthy controls and infertile women

\begin{tabular}{lll}
\hline Subjects & Age (years) & Weight $(\mathrm{kg})$ \\
\hline Healthy controls & $32.96 \pm 6.01$ & $60.96 \pm 3.34$ \\
Infertile women & $33.76 \pm 5.91$ & $64.63 \pm 3.42$ \\
\hline
\end{tabular}


Table 2: Comparison of biochemical parameters of healthy and infertile women

\begin{tabular}{llllll}
\hline Subjects & $\mathbf{H b}(\mathrm{g} / \mathrm{dl})$ & $\mathbf{T 3}(\mathbf{n g} / \mathbf{m l})$ & $\mathbf{T 4}(\boldsymbol{\mu g} / \mathbf{m l})$ & TSH $(\boldsymbol{\mu I U} / \mathbf{m l})$ & Prolactin $(\mathrm{ng} / \mathbf{m l})$ \\
\hline Healthy controls & $11.06 \pm 0.51$ & $1.11 \pm 0.34$ & $7.53 \pm 1.75$ & $0.98 \pm 0.71$ & $11.68 \pm 1.4$ \\
Infertile women & $10.76 \pm 0.61$ & $1.13 \pm 0.33$ & $9.62 \pm 2.68$ & $4.54 \pm 0.75$ & $86.83 \pm 3.88$ \\
\hline
\end{tabular}

\section{RESULTS AND DISCUSSION}

The average age of healthy subjects and infertile women was 32 years and 33 years, respectively. The mean weight of thirty infertile women was found to be higher as compared to healthy controls (Table 1).

Thelevel of hemoglobin was found to be slightly higher in healthy subjects $(11.6 \pm 0.51 \mathrm{~g} / \mathrm{dl})$ as compared to infertile women $(10.76 \pm 0.61 \mathrm{~g} / \mathrm{dl})$ (Table 2). The T3 levels of both healthy $(1.11 \pm 0.34 \mathrm{ng} / \mathrm{ml})$ and infertile women $(1.13 \pm 0.33 \mathrm{ng} / \mathrm{ml})$ were not significantly different.

Physiological rise in T3 level is seen in pregnancy usually and is more active hormone at the cellular level. Mild decrease in this hormone may have a significant effect on ovarian functions. High T4 levels confirm the diagnosis of hyperthyroidism. The mean value of T4 level is higher $(9.62 \pm 2.68 \mu \mathrm{g} / \mathrm{ml})$ in infertile women as compared to healthy controls $(7.53 \pm 1.75 \mu \mathrm{g} / \mathrm{ml})$. The TSH levels were found to be higher in infertile women $(4.54 \pm 0.75 \mu \mathrm{IU} / \mathrm{ml})$ as compared to the healthy controls $(0.98 \pm 0.71 \mu \mathrm{IU} / \mathrm{ml})$. With primary thyroid failure, the circulating thyroid hormone level falls, stimulate the pituitary gland to increase TSH output. Nearly, all women with elevated TSH levels had hypothyroidism. Menstrual irregularities and bleeding problems are common in hypothyroid women. The prolactin levels were found in the range of $21-161.4 \mathrm{ng} / \mathrm{ml}$ in infertile women under the study. The raised levels of prolactin showing hyperprolactinemia were found in infertile women $(86.83 \pm 3.88 \mathrm{ng} / \mathrm{ml})$ as compared to healthy controls $(11.68 \pm 1.4 \mathrm{ng} / \mathrm{ml})$. Hyperprolactinemia suppresses gonadal function and also reduces gonadotropin-releasing hormones and interferes with ovulation. Highest prolactin level $(161.4 \mathrm{ng} / \mathrm{ml})$ and highest TSH level $(5.68 \mu \mathrm{IU} / \mathrm{ml})$ were found in the infertile women with the highest weight of $78 \mathrm{~kg}$, recorded in the present study. From the data, it has been observed that high prolactin values were found in infertile women $70 \mathrm{~kg}$ of weight.

In the present study, the crude prevalence of hypothyroidism was slightly higher in comparison with that of normal subjects. Infertility and hypothyroidism also have digestive insufficiency because of low gastric acid secretion, which is essential for iron uptake. Heme, major group of hemoglobin, is bonded to thyroid peroxidase (TPO), the enzyme that releases iodine to tyrosine needed to form both thyroid hormones, T3 and T4. Inadequate iron leads to low TPO binding and low thyroid hormone synthesis. Low thyroid hormones alter the rate of heme oxidation in the liver and lead to iron deficiency. Lack of iron can alse lead to anovulation during the menstrual cycle. This affects the health of the egg to be fertilized $[10,11]$.

Thyroid hormones have a profound effect on reproduction and pregnancy. Thyroid dysfunctions are responsible for broad-spectrum reproductive disorders. This common cause of infertility can be managed by correcting the levels of thyroid hormones. Evaluation of thyroid status in the infertile couple significantly important because its treatment is very simple and might have reversible or preventable effects on infertility $[12,13]$. Hormone replacement therapy might have corrected the levels of thyroid hormones to combat infertility in case of subclinical hypothyroidism at an early stage. There is a significant change in thyroid hormone metabolism in pregnancy. In a woman with poor thyroid reserve, thyroid deficit state occurs due to increased urinary loss of thyroxine due to increase in glomerular filtration rate and placental transfer of thyroxine to growing fetus. Hence, there is an increased requirement for thyroid hormone during pregnancy in the first trimester of pregnancy [14]. The study of hormonal state is essential in the diagnosis of infertility and treatment [15]. Further hormonal studies should be planned with larger sample sizes for validation of variation in TSH and prolactin levels in the treatment of infertility.

\section{REFERENCES}

1. Kamel RM. Management of the infertile couple: An evidence-based protocol. Reprod Biol Endocrinol 2010;8:21.

2. Singla R, Gupta Y, Khemani M, Aggarwal S. Thyroid disorders and polycystic ovary syndrome: An emerging relationship. Indian J Endocrinol Metab 2015;19:25-9.

3. Sharma S, Khinehi MP, Sharma N, Aggarwal D, Gupta MK. Female infertility: An overview. Int J Pharm Sci Res 2011;1:1-12.

4. Grattan DR, Jasani CL, Liu X, Andersen GM, Harbisen AE. Prolactin regulation of gonadotrophin-releasing hormone neurons to suppress leutinizing hormone secretion in mice. Endocrinology 2007:148:4344-51

5. Pasquali R. Obesity and androgens: Facts and perspectives. Fertil Steril 2006;85:1319-40.

6. Raju GA, Chavan R, Deenadayal M, Gunasheela D, Gutgutia R, Haripriya $\mathrm{G}$, et al. Luteinizing hormone and follicle stimulating hormone synergy: A review of role in controlled ovarian hyperstimulation. J Hum Reprod Sci 2013;6:227-34.

7. Green KA, Werner MD, Franasiak JM, Juneau CR, Hong KH, Scott RT Jr. Investigating the optimal preconception TSH range for patients undergoing IVF when controlling for embryo quality. J Assist Reprod Genet 2015;32:1469-76

8. Louis B. The determination of hemoglobin by the acid hematin method. Arch Intern Med 1919;24:553-6.

9. Sánchez-Carbayo M, Mauri M, Alfayate R, Miralles C, Soria F. Analytical and clinical evaluation of TSH and thyroid hormones by electrochemiluminescent immunoassays. Clin Biochem 1999;32:395-403.

10. Sathiyanarayanan SK, Sundar JS, Madhavkumar EK, Praneeta A, Kalaiselvi S, Gopinath PM, et al. A study on significant biochemical changes in the serum of infertile women. Int J Curr Res Acad Rev 2014;2:96-115

11. Fayadat L, Niccoli-Sire P, Lanet J, Franc JL. Role of heme in intracellular trafficking of thyroperoxidase and involvement of $\mathrm{H} 2 \mathrm{O} 2$ generated at the apical surface of thyroid cells in autocatalytic covalent heme binding. J Biol Chem 1999;274:10533-8

12. Trokoudes KM, Skordis N, Picolos MK. Infertility and thyroid disorders. Curr Opin Obstet Gynecol 2006;18:446-51.

13. Poppe K, Velkeniers B, Glinoer D. Thyroid disease and female reproduction. Clin Endocrinol (Oxf) 2007;66:309-21.

14. Hebber S, Kumar S, Amin S, Doizode S. Subclinical hypothyroidism in pregnancy, is there a need for pharmacological intervention? Int $\mathrm{J}$ Pharm Pharm Sci 2017;9:186-91

15. Hakeim HK, Jebui IM, Rahim AI. Sirt6 is correlated with estradiol in women with in-vitro fertilization failure. Int J Pharm Pharm Sci 2016;8:184-8. 